Article

\title{
Association between Insomnia and Irritable Bowel Syndrome among Adolescents in South Korea: A Quantitative Cross-Sectional Study
}

\author{
Yun-Yi Yang (1)
}

check for updates

Citation: Yang, Y.-Y. Association between Insomnia and Irritable Bowel Syndrome among Adolescents in South Korea: A Quantitative Cross-Sectional Study. Adolescents 2021, 1, 500-507. https://doi.org/ 10.3390/adolescents1040038

Academic Editor: Laura L. Hayman

Received: 13 November 2021

Accepted: 8 December 2021

Published: 13 December 2021

Publisher's Note: MDPI stays neutral with regard to jurisdictional claims in published maps and institutional affiliations.

Copyright: (C) 2021 by the author. Licensee MDPI, Basel, Switzerland. This article is an open access article distributed under the terms and conditions of the Creative Commons Attribution (CC BY) license (https:// creativecommons.org/licenses/by/ $4.0 /)$.
Department of Nursing, Healthcare Science \& Human Ecology, Dong-Eui University, Busan 47340, Korea; yangyunyi@deu.ac.kr; Tel.: +82-51-890-4253

\begin{abstract}
Insomnia refers to having difficulty sleeping even when given the opportunity and environment to sleep. Irritable bowel syndrome is a functional bowel disease that is accompanied by abdominal pain and irregular defecation but not organic lesions. Although insomnia and irritable bowel syndrome are pathophysiologically related, studies on their relationship among adolescents are lacking. This study aimed to determine the prevalence of insomnia and irritable bowel syndrome among adolescents and the association between them. In May 2021, a survey was conducted among high school adolescents from Daegu Metropolitan City, South Korea, using the Korean version of the Insomnia Severity Index and the Rome IV diagnostic criteria for irritable bowel syndrome. Data were analyzed using chi-square and Mann-Whitney tests and logistic regression analyses. The incidence of insomnia (Insomnia Severity Index score $\geq 10)$ was $18.4 \%(n=74)$ while that of irritable bowel syndrome was $10.7 \%(n=43)$. Irritable bowel syndrome was strongly associated with an increased incidence of insomnia (odds ratio $=3.30,95 \%$ confidence interval: $1.66-6.53$ ). Therefore, the association between insomnia and irritable bowel syndrome has relevance in the treatment of insomnia in adolescents.
\end{abstract}

Keywords: irritable bowel syndrome; insomnia; Rome IV; sleep; adolescents

\section{Introduction}

Insomnia is a condition in which an individual finds it difficult to sleep despite having the opportunity and environment for adequate sleep. It is a subjective symptom characterized by difficulty in falling asleep (delayed sleep onset), difficulty in maintaining sleep (sleep fragmentation), early awakening, and nonrestorative sleep [1]. Adolescents are particularly vulnerable to insomnia, as adolescence is a period of substantial physical and psychological change [2]. The onset of insomnia during this period causes not only sleep-related issues, but also affects the sexual maturation of adolescents as well as their social and emotional development [2].

Irritable bowel syndrome (IBS) is a chronic functional gastrointestinal disorder accompanied by abdominal pain and changes in the form of bowel movements without the presence of organic lesions [3]. Although the cause of IBS has not been clearly identified, it is reported that gastrointestinal symptoms occur when genetic and psychological factors, such as depression, anxiety, and stress, cause changes in gastrointestinal motility and sensitivity and affect the gut microbiota and the regulation of the gut-brain interactions [4]. Globally, the prevalence of IBS among people aged 15 years or older is 8.8-14\% [5]; however, its prevalence is higher among adolescents, at 16.5-38.4\% [6-9]. In addition, insomnia among adolescents goes beyond the undesirable psychological effects of sleep deprivation or false perception of sleep states, having adverse physical effects as well, including functional cortical changes and systemic inflammation [10]. Related studies concerning adults reported a strong association between the pathophysiological mechanisms of insomnia and IBS [11,12]. However, there was no significant association between insomnia and IBS 
in a previous study of adolescents [9]. Additionally, a recent meta-analysis suggested the need for specific studies on insomnia and IBS among adolescents [13]. Despite this, only a few studies have examined the association between insomnia and IBS among adolescents, and none were conducted in South Korea. To bridge this gap, this study was conducted to determine the prevalence of insomnia and IBS among high school adolescents in South Korea and to investigate the association between the two disorders.

\section{Materials and Methods}

\subsection{Research Design}

This cross-sectional study aimed to determine the association between insomnia and IBS and was conducted in two high schools in Daegu Metropolitan City, South Korea.

\subsection{Setting and Participants}

The participants included adolescents attending high school. However, participants recruited by the researcher were asked whether they had organic digestive disorders (e.g., Crohn's disease, lactose malabsorption, colon cancer, obstructive bowel disease, etc.) or were taking sleep medication (e.g., sleeping pills, sleep inducers, etc.) and were excluded if appropriate. South Korean high schools consist of three grades, with students aged 15 years or older. The number of participants needed for this study was calculated using G-Power 3.12 software. Based on a logistic regression analysis, 409 participants were recruited for this study, which was the minimum sample size needed to maintain a significance level of 0.05 , an effect size of 1.5 , and a power of 0.90 . Seven participants were excluded for incomplete responses to the questionnaires, and the data from 402 participants were analyzed (response rate: $99.5 \%$ ).

\subsection{Research Tools}

\subsubsection{Demographic Characteristics}

Demographic characteristics comprised seven items: age, drinking status, smoking status, presence of a sleeping partner in the same room, mean total sleep time per week, mean exercise time per week, and mean smartphone usage time.

\subsubsection{Insomnia}

Developed by Bastien et al. [14], the Insomnia Severity Index (ISI) is a tool used to evaluate the severity of insomnia according to the diagnostic criteria of the Diagnostic and Statistical Manual of Mental Disorders IV and the International Classification of Sleep Disorders. This study used the Korean version of the K-ISI adapted by Cho et al. [14]. The seven-item tool is based on a five-point Likert scale to evaluate the severity of insomnia over the previous two weeks, the degree of satisfaction regarding the current sleep pattern, the degree to which sleep problems interfere with daytime functioning, the degree of impairment due to sleep problems, and the degree of concern about sleep problems. The total score is interpreted as follows: absence of insomnia (0-7), sub-threshold insomnia (8-14), moderate insomnia (15-21), and severe insomnia (22-28) [15]. This study followed the interpretation of a previous study [15] that classified a score of 10 or more as indicative of insomnia. At the time of its development, the ISI had a Cronbach's $\alpha$ of 0.74 and the K-ISI, adapted by Cho et al. [16], had a Cronbach's $\alpha$ of 0.87 , while its Cronbach's $\alpha$ in this study was 0.72 .

\subsubsection{IBS}

For the diagnosis of IBS, this study used the IBS module for children and adolescents that was developed by Hyams et al. [17] based on the Rome IV criteria and then translated by Han et al. [18]. The tool comprises 10 items, and the diagnostic criteria for IBS refer to symptoms that began at least two months ago; abdominal pain at least once a week for the past two months; and meeting one or more of the following three criteria: (1) improvement of symptoms after a bowel movement, (2) a change in the frequency of bowel movements, 
and (3) a change in the form of the bowel movements. The criteria for classifying IBS symptom type were based on two items relating to the differences in the frequency of diarrhea and constipation. If the frequency of occurrence of diarrhea and constipation are similar, the symptom type is classified as mixed type, and if there are no instances of diarrhea or constipation, it is regarded as an unclassified type.

\subsection{Data Collection}

The data were collected over a period of 10 days from 12 to 21 May 2021. After obtaining approval from the heads of two high schools in Daegu Metropolitan City, South Korea, the researcher directly distributed and collected consent forms and questionnaires from students who voluntarily agreed to participate in the study. The researcher fully explained to the participants the study inclusion and exclusion criteria, purpose, necessity, and procedure. Participants were informed that they could withdraw from the study at any point without penalty.

\subsection{Data Analysis and Statistical Methods}

The collected data were analyzed using the SPSS/WIN 22.0, as follows. Frequencies and percentages, as well as the mean and standard deviations, were calculated to determine participants' demographic characteristics, prevalence of insomnia, and severity of insomnia. Based on the differences in demographic characteristics and the prevalence of IBS corresponding to the prevalence of insomnia, the chi-square test was used to analyze the nominal variables, while the Mann-Whitney test was used to analyze the continuous variables, as the normality of these variables was not verified. A logistic regression analysis was conducted based on the prevalence of insomnia to determine the association between insomnia and IBS.

\section{Results}

\subsection{Demographic Characteristics}

The mean age of the participants was $16.87( \pm 0.7)$ years. Among the participants, $278(69.2 \%)$ were boys and $124(30.8 \%)$ were girls. Among them, $32(8.0 \%)$ said they were smokers and had smoked over the last two weeks, while $49(12.2 \%)$ said they were used to drinking and had consumed alcohol in the last two weeks. Of the participants, 33 (8.2\%) had a partner who slept with them in the same room. In addition, participants' mean sleep time was $387.6 \mathrm{~min} /$ day $( \pm 63.0)$. Their mean exercise time was $62.2 \mathrm{~min} /$ day $( \pm 55.0)$, and their mean smartphone usage time was $165.6 \mathrm{~min} /$ day $( \pm 112.2)$ (Table 1).

Table 1. Demographic characteristics $(n=402)$.

\begin{tabular}{ccc}
\hline Variable & Category or Range & Mean \pm SD or $\boldsymbol{n}(\mathbf{\%})$ \\
\hline Age & $15-18$ & $16.87 \pm 0.72$ \\
\hline \multirow{2}{*}{ Sex } & Boy & $278(69.2)$ \\
& Girl & $124(30.8)$ \\
\hline \multirow{2}{*}{ Smoking } & Yes & $32(8.0)$ \\
& No & $370(92.0)$ \\
\hline \multirow{2}{*}{ Drinking } & Yes & $49(12.2)$ \\
Sleeping partner & No & $353(87.8)$ \\
\hline Sleeping time (min/day) & Yes & $33(8.2)$ \\
\hline Exercise time (min/day) & No & $369(91.8)$ \\
\hline Smart phone using time & $180-600$ & $387.59 \pm 62.96$ \\
(min/day) & $0-320$ & $62.19 \pm 54.96$ \\
\hline
\end{tabular}




\subsection{Prevalence and Severity of Insomnia in Participants}

Of the participants, 74 (18.4\%) had a score indicative of insomnia (ISI score $\geq 10)$, and the average severity of insomnia was $5.76( \pm 4.14)$ points (Table 2$)$.

Table 2. Severity and prevalence of insomnia $(n=402)$.

\begin{tabular}{ccc}
\hline Variable & Category or Range & Mean \pm SD or $\boldsymbol{n}(\mathbf{\%})$ \\
\hline \multirow{2}{*}{ Insomnia $(\geq$ ISI score 10) } & Yes & $74(18.4)$ \\
& No & $328(81.6)$ \\
\hline Insomnia severity & $0-22$ & $5.76 \pm 4.14$ \\
\hline
\end{tabular}

ISI = Insomnia Severity Index.

\subsection{Prevalence and Subtypes of IBS in Participants}

Of the participants, $43(10.7 \%)$ had IBS according to the Rome IV criteria. Regarding the subtypes of IBS, two participants $(4.7 \%)$ were classified as "constipation-predominant", four $(9.3 \%)$ were "diarrhea-predominant", 32 (74.4\%) were "mixed", and five (11.6\%) were in the "unclassified" category (Table 3 ).

Table 3. Prevalence of IBS diagnosed by Rome IV and distributions of IBS subtypes $(n=402)$.

\begin{tabular}{ccc}
\hline Variable & Category & $\boldsymbol{n}(\mathbf{\%})$ \\
\hline \multirow{2}{*}{ IBS } & Yes & $43(10.7)$ \\
& No & $359(89.3)$ \\
\hline IBS subtypes & Constipation-predominant & $2(4.7)$ \\
\hline & Diarrhea-predominant & $4(9.3)$ \\
& Mixed & $32(74.4)$ \\
& Unclassified & $5(11.6)$ \\
\hline
\end{tabular}

$\overline{\mathrm{IBS}}=$ irritable bowel syndrome.

3.4. Differences in Demographic Characteristics and the Prevalence of IBS Corresponding to the Prevalence of Insomnia

The following differences were identified based on the prevalence of insomnia in the participants: smokers $\left(\chi^{2}=8.44, p=0.004\right)$ and IBS $\left(\chi^{2}=14.31, p<0.001\right)$. However, there were no differences based on the prevalence of insomnia in terms of the following: age $(\mathrm{U}=11.85, p=0.725)$, alcohol consumption $\left(\chi^{2}=1.37, p=0.241\right)$, sleep partner $\left(\chi^{2}=0.01\right.$, $p=0.972)$, exercise time $(U=11.93, p=0.819)$, smartphone usage time $(U=12.01, p=0.887)$, and sleep time $(\mathrm{U}=11.18, p=0.290)$ (Table 4$)$.

Table 4. Comparison of characteristics between insomnia and non-insomnia groups $(n=402)$.

\begin{tabular}{|c|c|c|c|c|c|}
\hline \multirow{3}{*}{ Variable } & \multirow{3}{*}{ Category } & \multicolumn{2}{|c|}{ Insomnia } & \multirow{3}{*}{$\chi^{2}$ or $\mathrm{U}$} & \multirow{3}{*}{$p$} \\
\hline & & Yes $(n=74)$ & No $(n=328)$ & & \\
\hline & & $\begin{array}{c}\text { Mean } \pm \text { SD } \\
\text { or } n(\%)\end{array}$ & $\begin{array}{l}\text { Mean } \pm \text { SD } \\
\quad \text { or } n(\%)\end{array}$ & & \\
\hline Age & & $16.84 \pm 0.81$ & $16.87 \pm 0.70$ & 11.85 & $0.725+$ \\
\hline \multirow{2}{*}{ Sex } & Boy & $53(71.6)$ & $225(68.6)$ & \multirow{2}{*}{0.26} & \multirow{2}{*}{0.611} \\
\hline & Girl & $21(28.4)$ & $103(31.4)$ & & \\
\hline \multirow{2}{*}{ Smoking } & Yes & $12(16.2)$ & $20(6.1)$ & \multirow{2}{*}{8.44} & \multirow{2}{*}{0.004} \\
\hline & No & $62(83.8)$ & 308 (93.9) & & \\
\hline \multirow{2}{*}{ Drinking } & Yes & $12(16.2)$ & $37(11.3)$ & \multirow{2}{*}{1.37} & \multirow{2}{*}{0.241} \\
\hline & No & $62(83.8)$ & $291(88.7)$ & & \\
\hline \multirow{2}{*}{ Sleeping partner } & Yes & $6(8.1)$ & $27(8.2)$ & \multirow{2}{*}{0.01} & \multirow{2}{*}{0.972} \\
\hline & No & $68(91.9)$ & $301(91.8)$ & & \\
\hline
\end{tabular}


Table 4. Cont.

\begin{tabular}{|c|c|c|c|c|c|}
\hline \multirow[b]{3}{*}{ Variable } & \multirow{3}{*}{ Category } & \multicolumn{2}{|c|}{ Insomnia } & \multirow{3}{*}{$\chi^{2}$ or $\mathrm{U}$} & \multirow{3}{*}{$p$} \\
\hline & & Yes $(n=74)$ & No $(n=328)$ & & \\
\hline & & $\begin{array}{l}\text { Mean } \pm \text { SD } \\
\quad \text { or } n(\%)\end{array}$ & $\begin{array}{l}\text { Mean } \pm \text { SD } \\
\text { or } n(\%)\end{array}$ & & \\
\hline \multicolumn{2}{|l|}{$\begin{array}{l}\text { Exercise time } \\
(\mathrm{min} / \text { day })\end{array}$} & $63.59 \pm 57.95$ & $61.87 \pm 0.70$ & 11.93 & $0.819+$ \\
\hline \multicolumn{2}{|l|}{$\begin{array}{l}\text { Smart phone using } \\
\text { time } \\
\text { (min/day) }\end{array}$} & $159.43 \pm 109.83$ & $166.97 \pm 112.83$ & 12.01 & $0.887+$ \\
\hline \multicolumn{2}{|l|}{$\begin{array}{l}\text { Sleeping time } \\
\text { (min/day) }\end{array}$} & $377.46 \pm 69.70$ & $389.88 \pm 61.23$ & 11.18 & $0.290+$ \\
\hline \multirow{2}{*}{ IBS } & Yes & $17(23.0)$ & $26(7.9)$ & \multirow{2}{*}{14.31} & \multirow{2}{*}{$<0.001$} \\
\hline & No & $57(77.0)$ & $302(92.1)$ & & \\
\hline
\end{tabular}

IBS = irritable bowel syndrome-; † Mann-Whitney U test.

\subsection{Regression Analysis According to the Prevalence of Insomnia}

Of the different logistic regression analysis methods, this study used the Wald backward elimination method with prevalence of insomnia as the dependent variable and the demographic characteristics and prevalence of IBS as independent variables. The final model was statistically significant $\left(\chi^{2}=17.89, p<0.001\right)$. The Hosmer-Lemeshow test $\left(\chi^{2}=0.086, p=0.769\right)$ demonstrated the goodness-of-fit of the final model with the data. Using this model to classify participants based on the prevalence of insomnia, $81.6 \%$ were correctly classified overall, and the final significant variables were smoking status $(\mathrm{OR}=2.76,95 \%$ CI: $1.26-6.07)$ and IBS (OR = 3.30, 95\% CI: 1.66-6.53) (Table 5).

Table 5. Factors affecting insomnia prevalence among the participants $(n=402)$.

\begin{tabular}{|c|c|c|c|c|c|c|c|}
\hline \multirow{2}{*}{ Variable } & \multirow{2}{*}{ Category } & \multirow{2}{*}{ B } & \multirow{2}{*}{ SE } & \multirow{2}{*}{ OR } & \multicolumn{2}{|c|}{$95 \%$ CI } & \multirow{2}{*}{$p$} \\
\hline & & & & & Lower & Upper & \\
\hline \multirow{2}{*}{$\begin{array}{l}\text { Smoking } \\
\text { IBS }\end{array}$} & Yes & 1.02 & 0.40 & 2.76 & 1.26 & 6.07 & 0.011 \\
\hline & Yes & 1.19 & 0.35 & 3.30 & 1.66 & 6.53 & 0.001 \\
\hline \multicolumn{8}{|c|}{$\begin{aligned}-2 \log \text { Likelihood }= & 366.04, \text { Hosmer and Lemeshow test: } \chi^{2}=0.09, p=0.769 \\
& \text { correct classification }(\%)=81.6 \%\end{aligned}$} \\
\hline
\end{tabular}

\section{Discussion}

This study aimed to determine the prevalence of insomnia and IBS among adolescents and investigate the association between the two disorders. Among the study participants $(n=402)$, the incidence of insomnia (ISI score $\geq 10)$ was $18.4 \%(n=74)$ and the mean insomnia severity score of all the participants was $5.76( \pm 4.14)$ points, which were within the normal range. This result is similar to the incidence of insomnia (ISI score $\geq 9$ ) among adolescents in Hong Kong (12.9\%) [19], and the mean insomnia severity score among adolescents in Germany, which is $5.91( \pm 4.13)$ points [20].

The incidence of IBS (Rome IV criteria) among the study participants was 10.7\% $(n=43)$. This result is lower than the IBS incidence in both Indonesian adolescents (male: $62.9 \%$ ) [9], which is $38.4 \%$, and Japanese adolescents, which is $18.6 \%$ [7] based on the Rome III criteria. However, the IBS incidence among this study's participants was higher than that in Colombian adolescents, which is $2.3 \%$ (male: $45 \%$ ) [21] based on the same Rome IV criteria used in this study. When the diagnosis rates of IBS were compared based on the Rome III or Rome IV criteria, the rate of diagnosis was lower with the Rome IV criteria [21], which indicates the need for further research on the incidence of IBS among adolescents with regard to the Rome IV criteria. 
Per the current findings, the prevalence of IBS among adolescents increased the incidence of insomnia by a factor of 3.3. This finding is similar to that of a study on Japanese adolescents [7], which reported that sleep problems were significantly associated with IBS. However, the results differ from a study on Indonesian adolescents [9], which found no association between IBS and insomnia. A systematic review of the association between IBS and sleep problems reported a strong association between insomnia and IBS [11]. Although the reason for this is not clear, it is speculated that the relationship between the two disorders is a vicious cycle that is closely related to the gut-brain axis [13]. In a previous study, IBS was associated with a delay in sleep onset in adolescents, which is a symptom of insomnia [7]. Future studies should investigate the specific symptoms of IBS that cause delayed sleep onset. Based on the results of this study, a relational approach between IBS and insomnia is mandated in the treatment of IBS and insomnia in adolescents.

In addition, smoking was found to increase the incidence of insomnia in adolescents by a factor of 2.76. This is similar to the findings of a previous study [19], which found an association between smoking and insomnia in adolescents. The risk of insomnia was found to increase in adults who started smoking during mid-adolescence [22]. Another study reported that nicotine in cigarettes interferes with sleep by stimulating the release of neurotransmitters responsible for the release of dopamine and serotonin, which has a negative pathophysiological effect on the brain and the central nervous system [23]. It has been ascertained that patients with IBS (diarrhea- and constipation-predominant types) have high serotonin levels in their blood and urine and abnormalities in the secretion and regulation of serotonin are a major factor in the development of IBS [24]. However, one systematic review [25] found no significant association between smoking and IBS. Future studies should investigate the association between smoking and serotonin for each subtype of IBS.

No significant sex differences were found concerning insomnia. This differs from a prior study that showed that women are vulnerable to insomnia [10]. However, in a recent study of adolescents [9], there was no relationship between sex and insomnia, which coincides with the current findings. In addition, there was no significant difference between exercise time, smartphone use time, and insomnia in this study, similar to the previous results [9]. In this study, the presence or absence of a sleep partner and the duration of sleep were not significantly associated with the occurrence of insomnia. This suggests that insomnia in adolescence is associated with dissatisfaction with the quality of one's sleep rather than the quantity, in addition to physiological responses such as smoking and IBS symptoms rather than sleep environmental conditions such as sleeping in the same room as a partner.

This study is significant because it is the first in South Korea to investigate the association between insomnia and IBS in adolescents. However, this study also has several limitations. First, the research findings cannot be generalized as this study examined high school students from only one region of South Korea. Second, sleep-related IBS symptoms (such as gastrointestinal symptoms during sleep) and physiological variables (melatonin, serotonin, etc.) were not investigated. Further investigations into sleep-related IBS symptoms would help understand the association between IBS and insomnia.

\section{Conclusions}

The present study determined the prevalence of insomnia and IBS among adolescents in South Korea and investigated the association between insomnia and IBS. The prevalence of insomnia was $18.4 \%$ and that of IBS was $10.7 \%$. In addition, this study found a strong association between IBS and insomnia in adolescents. Thus, it is necessary to investigate the symptoms of IBS affecting insomnia when treating insomnia in adolescents and include them in the treatment plan.

Funding: This research received no external funding. 
Institutional Review Board Statement: The study was conducted according to the guidelines of the Declaration of Helsinki and approved by the Institutional Review Board (DIRB-202105-HR-E-06) to which the researcher belongs.

Informed Consent Statement: Informed consent was obtained from all subjects involved in the study.

Data Availability Statement: The data presented in this study are available on request from the corresponding author. However, to maintain confidentiality, the data are not publicly available.

Conflicts of Interest: The author declares no conflict of interest.

\section{References}

1. American Academy of Sleep Medicine (AASM). International Classification of Sleep Disorders; American Academy of Sleep Medicine: Westchester, IL, USA, 2005.

2. Kang, S.H.; Yoo, H.K.; Chung, S.; Kim, C.Y. Eveningness, Sleep patterns, Daytime sleepiness and fatigue in Korean male adolescents. Sleep Med. Psychophysiol. 2012, 19, 89-96.

3. Drossman, D.A. The functional gastrointestinal disorders and the Rome III process. Gastroenterology 2006, 130, 1377-1390. [CrossRef] [PubMed]

4. Han, S.H.; Lee, O.Y.; Bae, S.C.; Lee, S.H.; Chang, Y.K.; Yang, S.Y.; Yoon, B.C.; Choi, H.S.; Hahm, J.S.; Lee, M.H.; et al. Prevalence of irritable bowel syndrome in Korea: Population-based survey using the Rome II criteria. J. Gastroenterol. Hepatol. 2006, 21, 1687-1692. [CrossRef] [PubMed]

5. Lovell, R.M.; Ford, A.C. Global prevalence of and risk factors for irritable bowel syndrome: A meta-analysis. Clin. Gastroenterol. Hepatol. 2012, 10, 712.e4-721.e4. [CrossRef]

6. Zhou, H.-Q.; Yao, M.; Chen, W.B.; Sun, M.F.; Cheng, G.Y.; Chen, Y.P.; Li, D.G. High prevalence of irritable bowel syndrome with poor sleep quality in children and adolescents in Shanghai. Sleep Biol. Rhythm. 2012, 10, 179-186. [CrossRef]

7. Yamamoto, R.; Kaneita, Y.; Osaki, Y.; Kanda, H.; Suzuki, K.; Higuchi, S.; Ikeda, M.; Kondo, S.; Munezawa, T.; Ohida, T. Irritable bowel syndrome among Japanese adolescents: A nationally representative survey. J. Gastroenterol. Hepatol. 2015, 30, 1354-1360. [CrossRef] [PubMed]

8. Choi, J. Clinical manifestations of irritable bowel syndrome and relationship between stress, family function and irritable bowel syndrome in high school students. J. Korean Acad. Fam. Med. 1996, 17, 11-21.

9. Noor, L.I.K.; Bakri, A.; Soejadhi, R.; Kesuma, Y. Association between irritable bowel syndrome and sleep disturbance in adolescents. Adolesc. Health Med. Ther. 2020, 11, 73-77.

10. de Zambotti, M.; Goldstone, A.; Colrain, I.M.; Baker, F.C. Insomnia disorder in adolescence: Diagnosis, impact, and treatment. Sleep Med. Rev. 2018, 39, 12-24. [CrossRef] [PubMed]

11. Tu, Q.; Heitkemper, M.M.; Jarrett, M.E.; Buchanan, D.T. Sleep disturbances in irritable bowel syndrome: A systematic review. Neurogastroenterol. Motil. 2017, 29, e12946. [CrossRef]

12. Morito, Y.; Aimi, M.; Ishimura, N.; Shimura, S.; Mikami, H.; Okimoto, E.; Sato, S.; Ishihara, S.; Kushiyama, Y.; Katsube, T.; et al. Association between sleep disturbances and abdominal symptoms. Intern. Med. J. 2014, 53, 2179-2183. [CrossRef]

13. Wang, B.; Duan, R.; Duan, L. Prevalence of sleep disorder in irritable bowel syndrome: A systematic review with meta-analysis. Saudi J. Gastroenterol. 2018, 24, 141-150. [PubMed]

14. Bastien, C.H.; Vallieres, A.; Morin, C.M. Validation of the Insomnia Severity Index as an outcome measure for insomnia research. Sleep Med. 2001, 2, 297-307. [CrossRef]

15. Cho, Y.W.; Song, M.L.; Morin, C.M. Validation of a Korean version of the Insomnia Severity Index. J. Clin. Neurol. 2014, 10, 210-215. [CrossRef]

16. Morin, C.M.; Belleville, G.; Bélanger, L.; Ivers, H. The Insomnia Severity Index: Psychometric indicators to detect insomnia cases and evaluate treatment response. Sleep 2011, 34, 601-608. [CrossRef] [PubMed]

17. Hyams, J.S.; Di Lorenzo, C.; Saps, M.; Shulman, R.J.; Staiano, A.; van Tilburg, M. Functional disorders: Children and adolescents. Gastroenterol 2016, 150, 456-1468. [CrossRef] [PubMed]

18. Han, Y.J.; Lee, S.H.; Lee, Y.J. A study on the influence of irritable bowel syndrome on dietary habits and fatigue in children and adolescents. J. Korean Oriental Pediatr. 2017, 31, 1-13.

19. Zhang, J.; Chan, N.Y.; Lam, S.P.; Li, S.X.; Liu, Y.; Chan, J.W.; Kong, A.P.S.; Ma, R.C.; Chan, K.C.; Li, A.M.; et al. Emergence of sex differences in insomnia symptoms in adolescents: A large-scale school-based study. Sleep 2016, 39, 1563-1570. [CrossRef]

20. Gerber, M.; Lang, C.; Lemola, S.; Colledge, F.; Kalak, N.; Holsboer-Trachsler, E.; Pühse, U.; Brand, S. Validation of the German version of the Insomnia Severity Index in adolescents, young adults and adult workers: Results from three cross-sectional studies. BMC Psychiatr. 2016, 16, 174. [CrossRef] [PubMed]

21. Saps, M.; Velasco-Benitez, C.A.; Langshaw, A.H.; Ramírez-Hernández, C.R. Prevalence of functional gastrointestinal disorders in children and adolescents: Comparison between Rome III and Rome IV criteria. J. Pediatr. 2018, 199, 212-216. [CrossRef]

22. Brook, J.S.; Zhang, C.; Seltzer, N.; Brook, D.W. Insomnia in adults: The impact of earlier cigarette smoking from adolescence to adulthood. J. Addict. Medi. 2015, 9, 40. [CrossRef] 
23. Liu, J.-T.; Lee, I.H.; Wang, C.H.; Chen, K.C.; Lee, C.I.; Yang, Y.K. Cigarette smoking might impair memory and sleep quality. J. Formos. Med. Assoc. 2013, 112, 287-290. [CrossRef]

24. Moskwa, A.; Chojnacki, J.; Wiśiewska-Jarosińska, M.; Stec-Michalska, K.; Szadkowski, K.; Smigielski, J.; Chojnacki, C. Serum serotonin concentration and urine 5-hydroxyindole acetic acid excretion in patients with irritable bowel syndrome. Polski. Merkur. Lek. Organ Pol. Tow. Lek. 2007, 22, 366-368.

25. Sirri, L.; Grandi, S.; Tossani, E. Smoking in irritable bowel syndrome: A systematic review. J. Dual. Diagn. 2017, 13, 184-200. [CrossRef] 